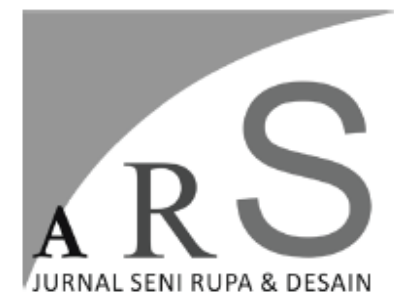

Volume 22 Nomor 2,

Agustus 2019

\title{
KAJIAN BUDAYA DUDUK JAWA SEBAGAI INTERAKSI SOSIAL DI PANTI WREDA YOGYAKARTA
}

\author{
Ganesha Puspa Nabila \\ Program Studi Magister Desain, Institut Teknologi Bandung, Indonesia \\ E-mail: ganeshabella@gmail.com
}

\begin{abstract}
ABSTRAK
Pada umumnya orang lanjut usia dalam meniti kehidupan yang ia jalani dikategorikan kedalam dua macam. Pertama, masa tua tersebut akan diterima dengan wajar melalui kesadaran yang mendalam, sedangkan yang kedua, manusia usia lanjut dalam menyikapi hidupnya cenderung menolak datangnya masa tua, kelompok ini tidak mau menerima realitas yang ada (Hurlock, 1996). Terdapat banyak kasus dimana pasien lansia justru merasa depresi dan mendapat tekanan stress ketika harus dirawat di fasilitas panti wreda. Namun hal ini diperburuk dengan kenyataan bahwa pada beberapa kasus panti wreda tidak memiliki sistem yang dapat memfasilitasi masa transisi pasien lanjut usia. Interaksi sosial diharapkan menjadi salah satu jawaban untuk menjawab permasalahan adaptasi diatas, sedangkan budaya duduk Jawa digunakan sebagai langkah pendekatan yang mengarah pada emotional design. Penelitian ini menggunakan pendekatan kualitatif deskriptif dengan metode studi pustaka. Dengan pengembangan teori interaksi sosial pada budaya duduk Jawa yang diterapkan pada pasien lansia di panti wreda, akan ditelaah lebih jauh terkait pengembangan teori di atas, sehingga hasil kajian berupa konsep-konsep dan arahan dalam merancang ruang dengan dasar environmental psychology, diharapkan dengan adanya penelitian ini dapat menjadi jembatan untuk mereaktualisasikan budaya duduk Jawa sebagai stimulus interaksi sosial di panti wreda yang dapat membantu proses adaptasi pasien lansia.
\end{abstract}

Kata kunci: budaya duduk, interaksi sosial, panti wreda

\section{ABSTRACT}

In general, the elderly's way of pursuing their life is categorized into two kind of phases. First, the phase of pension time will be accepted fairly through deep awareness, while the second, the elderly tends to reject the coming of pension time phase, this group does not want to accept reality (Hurlock, 1996). There are many cases in which elderly patients feel depressed and stressed when they have to be admitted to an elderly facilities care. This is exacerbated by the fact that in some cases the elderly care facilities do not have a system that can facilitate the transition and adaptation of elderly patients. Social interaction is expected to be one of the answers to adaptation problems mention above, while Javanese sitting culture is used as an strategical approach that leads to emotional design. This study uses a descriptive qualitative approach with a literature study method. With the development of the theory of social interaction in Javanese sitting culture applied to 
elderly patients in nursing homes, it will be explored further regarding the development of the above theory, so the results of the study in the form of concepts and directives in designing space with the basis of environmental psychology are expected with this research can be a bridge to re-actualize Javanese culture as a stimulus for social interaction in nursing homes that can help the process of adaptation to elderly patients.

Keywords: sitting culture, social interaction, elderly-care facilities

\section{Pendahuluan}

Kesejahteraan lanjut usia telah diatur dalam Undang-undang Republik Indonesia No.13 tahun 1998 Pasal 8 tentang Kesejahteraan Lanjut Sosial yang menerangkan bahwa pemerintah, masyarakat, dan keluarga bertanggungjawab atas terwujudnya upaya peningkatan kesejahteraan sosial lanjut usia. (www.kepustakaan-presiden.pnri.go.id,1998) Sedangkan terkait pelayanan kesehatan bagi lansia dibahas pula pada Peraturan Pemerintah Republik Indonesia No. 43 Tahun 2004 tentang Pelaksanaan Upaya Peningkatan Kesejahteraan Sosial Lanjut Usia bagian ketiga Pasal 8 alinea pertama yang menyatakan pelayanan kesehatan dimaksudkan untuk memelihara dan meningkatkan derajat kesehatan dan kemampuan lanjut usia agar kondisi fisik, mental, dan sosialnya dapat berfungsi secara wajar. (www.peraturan.go.id, 2004)

Berdasarkan undang-undang dan peraturan pemerintah tersebut, perlu adanya perhatian lebih pada sarana dan prasarana yang dapat menunjang pelayanan kesehatan fisik, mental dan sosial lansia. Terlebih adanya kebutuhan khusus pada kondisi psikologis dan fisik lansia. Seperti yang dikutip oleh (Jafar, Wiarsih, \& Permatasari, 2013) yang meneliti hubungan psiko-sosial lansia terhadap perpisahan keluarga menemukan bahwa dari 63 responden terdapat $27 \%$ responden yang termasuk kedalam kategori kecemasan berat, sedangkan $41,3 \%$ lainnya masuk kedalam kategori kecemasan sedang, perasaan kehilangan dan ketidakberdayaan biasanya dialami bersamaan.
Banyak penelitian terdahulu terkait interaksi sosial yang dialami oleh lansia di panti wreda dan pengaruhnya pada kualitas hidup lansia sehingga telah dinyatakan pula bahwa terdapat hubungan erat antara interaksi sosial pada lansia dengan kualitas hidup lansia. (Samper, Pinontoan, \& Katuuk, 2017) Disebutkan pula (Ariyani, 2013) bahwa perbedaan karakter penghuni panti wreda adalah salah satu hambatan dalam proses adaptasi lansia di panti wreda dimana kesadaran individu adalah faktor penentu kondisi psikologis lansia. Maka interaksi sosial menjadi satu poin penting dalam kebutuhan sehari-hari lansia di panti wreda.

Budaya duduk diambil sebagai media untuk mengangkat fungsi dari interaksi sosial pada pasien lansia di panti wreda.

\section{Rumusan Masalah}

Penelitian ini berfokus pada hubungan interaksi sosial yang terbangun dari pendekatan kultural berupa budaya duduk Jawa pada lansia di panti wreda.

\section{Tujuan Penelitian}

Tujuan dari penelitian ini adalah untuk mengetahui keterkaitan budaya duduk Jawa terhadap interaksi sosial lansia di panti wreda.

\section{Teori dan Metode}

Metodologi yang digunakan dalam studi ini adalah pendekatan kualitatif deskriptif dengan metode kajian teoritis. Dikarenakan masalah waktu yang menyebabkan kurang 
lengkapnya data untuk dianalisa lebih dalam, peneliti menyimpulkan kajian teoritis dengan metode kualitatif deskriptif diharapkan mampu menjawab pertanyaan penelitian.

\section{Budaya Duduk Jawa}

Koentjaraningrat

mengemukakan bahwa sistem nilai budaya terdiri dari konsepsi-konsepsi yang hidup dalam alam pikiran sebagian besar warga masyarakat, mengenai hal-hal yang harus mereka anggap amat bernilai dalam hidup. Sedangkan kebudayaan menurut UndangUndang Dasar 1945 pasal 32 kebudayaan bangsa adalah kebudayaan yang timbul sebagai buah usaha budinya rakyat Indonesia seluruhnya. Koentjaraningrat (1974:15) menyatakan bahwa adat tata kelakuan atau secara singkat disebut adat dalam arti khusus, atau adat istiadat dalam bentuk jamak merupakan bentuk ideal dari kebudayaan. Wujud lain dari kebudayaan sering disebut sistem sosial yang merupakan suatu kelakuan berpola dari manusia itu sendiri.

Perbedaan adat dan kebudayaan bersangkutan dengan konsepsi bahwa kebudayaan memiliki tiga wujud yaitu; wujud ideal, wujud kelakuan, dan wujud fisik. Sedangkan adat adalah wujud ideal dari kebudayaan ((Koentjaraningrat, 1974:20)

Penerapan pendekatan budaya pada penelitian ini didasari oleh kesimpulan bahwa budaya yang akhirnya menjadi identitas individu dapat dijadikan tumpuan yang mendasar dalam beradaptasi dan menyesuaikan diri di lingkungan yang baru.

Budaya duduk disini dimaknai oleh adat dan kebiasaan duduk masyarakat Jawa tidak lepas dari pengaruh kebudayaan dan perjalanan historis serta tatanan masyarakat Jawa pada umumnya. Masyarakat Jawa menganggap bahwa toleransi terhadap perbedaan status sosial untuk mendapatkan pemahaman lebih mendalam tentang struktur hirarki alam semesta. (Wiyancoko, 2000:36) Masih menurut Wiyancoko, aspek yang paling menonjol pada perilaku duduk pada kasus masyarakat Jawa adalah sikap interaksi yang terbangun dengan perilaku duduk.

Wiyancoko (2000) membagi gaya duduk dan postur duduk masyarakat Jawa kedalam tiga periode yang mempengaruhi perkembangan budaya duduk pada masyarakat Jawa sebagai berikut:

1. Periode Hindu-Buddha.

Pada periode ini raja-raja postur duduk pada singgasana disebut postur Sinowoko.

Postur siniwoko adalah postur duduk dengan punggung tegak dan kaki diberi tumpuan berupa bangku. Sedangkan masyarakat awam duduk dengan bersimpuh di lantai.

2. Periode Islam.

Pada periode Islam, penyebaran agama Islam di seluruh penjuru pulau Jawa memiliki dampak memperkuat tradisi perilaku duduk di lantai. Masyarakat awam Jawa semula duduk di lantai untuk beribadah di kuil-kuil Hindu dan Buddha kini masyarakat pemeluk Islam dan para santri duduk di lantai di Masjid dan pengajian.

3. Periode Kolonial Eropa.

Selama periode ini pemerintah kolonial mengirim furnitur bergaya Eropa dalam jumlah besar. Gaya duduk eropa yang menggunakan kursi kemudian diadaptasi oleh bangsawan Jawa dan pemegang kekuasaan setempat yang bekerja kepada pemerintah kolonial untuk merepresentasikan status sosial.

Jenis budaya duduk orang Jawa memerlukan pertimbangan berbagai bentuk lain dari perilaku duduk sebagai aktivitas nonverbal yang di rangkum dalam tiga masalah mendasar yaitu penggunaan, asal, dan pengkodean perilaku nonverbal. Arti coding disini adalah prinsip-prinsip korespondensi antara tindakan dan maknanya yang dipelajari dengan perhatian sadar dari budaya lain sebagai bagian dari interaksi sosial. Periode Hindu dan Islam menjadikan budaya duduk sebagai perilaku ritual pada budaya Jawa, sedangkan periode Eropa menjadikan budaya 
duduk sebagai tindakan untuk mewakili status sosial. (Wiyancoko, 2000)

\section{Interaksi Sosial}

$$
\text { Interaksi sosial menurut }
$$

(Partowisastro, 2003) Partowisastro (2003) adalah relasi sosial dengan tujuan terbentuknya hubungan dinamis, baik relasi antar individu, individu dengan kelompok, maupun antar kelompok. Sedangkan Soekanto (2002) menjelaskan bahwa aspek interaksi sosial terbagi dalam aspek kontak sosial dan aspek komunikasi.

Interaksi sosial yang terbentuk dari aspek komunikasi dan aspek kontak sosial memiliki bentuk-bentuk yang menurut Sarwono (2009) sebagai berikut :

1. Kerjasama

2. Persaingan

3. Konflik

4. Akomodasi

Jonathan $\quad H . \quad$ Turner mengemukakan dua asumsi utama yang pertama dalam $A$ Theory of Social Interaction yaitu bahwa interaksi sosial berada pada posisi pivot dalam unit dasar sosiologi dan yang kedua Turner menyatakan pula bahwa terdapat 3 poin utama dalam memahami interaksi yaitu; motivasi, interaksional dan struktur (Hegtvedt, 2014).

Motivasional yang merupakan latar belakang yang mempengaruhi manusia untuk terdorong melakukan interaksi, sedangkan poin interaksional berfokus pada mekanisme pemberian sinyal dan penangkapan sinyal dari orang lain melalui perilaku. Poin yang terakhir adalah struktur yang menunjukkan pengulangan interaksi yang merngarah pada pengembangan pola interaksi (Hegtvedt, 2014).

Sedangkan berdasarkan Robert Weiss (1974) The provisions of social relationships terdapat 6 fungsi dari hubungan sosial yang diperlukan agar individual merasa cukup didukung dan dapat menghindari perasaan kesepian, (Cutrona, Russell, \& Rose, 1986) yaitu;

1. Keterikatan (attachment)
Perasaan terikat, kedekatan dan kenyaman serta keamanan adalah perasaan yang biasanya berasal dari pasangan.

2. Integrasi sosial (social integration)

Pada fungsi ini rasa memiliki dalam suatu kelompok orang yang memiliki persamaan ketertarikan dan biasanya berasal dari teman.

3. Reassurance of worth

Perasaan diterima dan dan diakui secara kompetensi dan kemampuan biasanya berasal dari kolega.

4. Bimbingan (Guidance)

Nasihat dan informasi biasanya didapat dari guru, mentor atau figur orang tua

5. Opportunity for nurturance

Pada fungsi ini rasa tanggung jawab untuk kesejahteraan orang lain, biasanya diperoleh dari keberadaan anak.

Interaksi sosial yang dilakukan oleh lansia dengan sesama penghuni panti wreda ditimbulkan dengan dorongan kontak sosial yang berasal dari budaya duduk.

\section{Hasil Penelitian dan Pembahasan}

Menurut teori Cognitive

Consistency dari Fritz Heider yang dikutip oleh Rakhmat (2011:111) bahwa manusia selalu berusaha mencapai konsistensi dalam sikap dan perilakunya, Heider menyebutkan pula bahwa kita cenderung menyukai orang, kita ingin mereka memilih sikap yang sama dengan kita, dan jika kita menyukai orang, kita ingin mereka memilih sikap yang sama dengan kita.

Ditentukannya budaya duduk sebagai salah satu variabel pada penelitan ini didukung dengan pernyataan Rakhmat (2011) bahwa bila orang berada dalam keadaan yang mencemaskannya atau memikul tekanan emosional, ia akan menginginkan kehadiran orang lain. Dikutip oleh Rakhmat (2011) dikatakan oleh Schachter dalam penelitiannya bahwa situasi penimbul cemas (anxietyproducing situations) meningkatkan kebutuhan akan kasih sayang. Maka pada kondisi lingkungan di panti wreda dimana kondisi fisik dan psikologis lansia tidak lagi dalam keadaan 
optimal sedangkan berlangsung pula tuntutan untuk beradaptasi dengan lingkungan baru, interaksi sosial dapat menjadi salah satu jawaban.

Banyak faktor yang mempengaruhi terjadinya interaksi sosial, dan salah satunya adalah budaya duduk. Dengan adanya konsep gotong-royong dan guyub, maka interaksi kelompok menjadi poin penting pada masyarakat Jawa.

Konsep gotong-royong yang kita anggap tinggi itu merupakan suatu konsep yang erat bersangkut paut dengan kehidupan rakyat kita sebagai petani dalam masyarakat agraris. Istilahnya istilah Jawa, hanya saja dari mana di Jawa istilah itu berasal tidak jelas lagi. (Koentjaraningrat,1974:59) Fenomena gotongroyong yang kemudian melahirkan budaya guyub. Guyub menurut KBBI Kamus Besar Bahasa Indonesia adalah rukun, sedangkan berguyub adalah berkelompok; berkumpul.

Peran budaya duduk Jawa pada pembahasan ini diterapkan pada panti wreda yang berlokasi di Yogyakarta dengan mayoritas masyarakart Jawa dengan latar kebudayaan yang kental. Pertimbangan penerapan budaya duduk Jawa pada masyarakat Jawa di Yogyakarta. Berada pada kultur lingkungan membawa dampak rasa memiliki dan koneksi, sehingga diharapkan dapat mempengaruhi kondisi psikologi lansia di panti wreda. (Minde, 2015)

\section{Kesimpulan}

Ketika lansia dipindahkan ke fasilitas panti wreda mereka kehilangan hubungan dengan rumah asal dan lingkungan kultural mereka (Minde, 2015). Latar budaya yang telah menjadi identitas dari individu dijadikan media yang menjembatani kebutuhan psikologis lansia. Kegiatan duduk diasosiasikan dengan segala kebiasaan dan adatnya dibentuk kembali dengan berfokus pada fungsi dorongan untuk memulai interaksi sosial.

Interaksi tidak mudah dilakukan oleh lansia dengan kondisi fisik dan psikologis yang tidak lagi optimal, namun dengan setting lingkungan yang mengarah pada dorongan kontak sosial dan komunikasi diharapkan dapat menjawab permasalahan diatas.

\section{Daftar Pustaka}

Ariyani, A. M. (2013). Lansia Di Panti Werdha (Studi Deskriptif Mengenai Proses Adaptasi Lansia Di Panti Werdha Hargo Dedali Surabaya). Antopologi.

Cutrona, C., Russell, D., \& Rose, J. (1986). Social Support and Adaptation to Stress by the Elderly. Psychology and Aging, 1(January).

http://doi.org/10.1037//0882-

7974.1.1.47

Hegtvedt, K. (2014). A Theory of Social Interaction . by Jonathan $\mathrm{H}$. Turner Review by: Karen A. Hegtvedt Stable URL : http://www.jstor.org/stable/2579266. Social Forces, 68(2), 646-647.

Jafar, N., Wiarsih, W., \& Permatasari, H. (2013). Hubungan Dukungan Keluarga Dengan Perilaku Lansia Dalam Pengendalian Hipertensi.

Koentjaraningrat. (1974). Kebudayaan, Mentalitet, dan Pembangunan: Bungarampai. Jakarta: Gramedia.

Koentjaraningrat. (1983). Metode-metode Penelitian Masyarakat. Jakarta: Gramedia.

Minde, G.-T. (2015). A Culturally-sensitive Approach to Elderly Care. Journal of Gerontology \& Geriatric Research, 04(05). http://doi.org/10.4172/21677182.1000241

Nuurhidayat Jafar. (2011). Pengalaman Lanjut Usia Mendapatkan Dukungan Keluarga. Keperawatan Indonesia, Volume 14(No. 3, November).

Partowisastro, R. (2003). Perbandingan konsep diri dan Interaksi Sosial anak-anak remaja WNI asli dengan keturunan Tionghoa. Yogyakarta.

Rahmat, J. (2011). Psikologi Komunikasi. Bandung: Remadja Rosda Karja.

Samper, T. P., Pinontoan, O. R., \& Katuuk, M. E. (2017). Hubungan Interaksi Sosial dengan Kualitas Hidup Lansia di BPLU 
Senja Cerah Provinsi Sulawesi Utara. Ournal Keperawatan (, 5(1).

Sarwono. (2009). Psikologi Sosial. Jakarta: Salemba Humanika.

Sukanto. (2002). Sosiologi: Suatu Pengantar. Jakarta: Rajawali.

Weiss, R. (1974). The Provisions of Social Relationships. Englewood Cliffs: Prentice Hall.

Wiyancoko, D. (2000). Dimensi Kebudayaan
Dalam Desain. Bandung.

www.kepustakaan-presiden.pnri.go.id. (1998). Kesejahteraan Lanjut Sosial. Retrieved from www.kepustakaanpresiden.pnri.go.id

www.peraturan.go.id. (2004). Pelaksanaan Upaya Peningkatan Kesejahteraan Sosial Lanjut Usia. Jakarta. Retrieved from www.peraturan.go.id 